\title{
Microwaves increase the effectiveness of systemic antibiotic treatment in acute bone infection: experimental study in a rat model
}

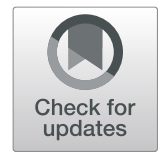

\author{
Xiao-yang Qi ${ }^{1,3},{ }^{\prime}$-sheng Qiu ${ }^{1,2^{*}}$, Jiang-yun Jiang ${ }^{1}$, Yi-xin Chen ${ }^{1,2^{*}} \mathbb{D}$, Li-ming Tang ${ }^{3}$ and Hong-fei Shi ${ }^{1,2}$
}

\begin{abstract}
Background: Osteomyelitis is a challenge for orthopedic surgeons due to its protracted treatment process. Microwaves (MWs) can increase blood perfusion due to their thermal effect. Furthermore, MWs demonstrated significant bactericidal effects in vitro. In the present study, we assumed that the application of a $2450-\mathrm{MHz}$-frequency MW together with systemic antibiotic treatment would provide synergy for the treatment of acute osteomyelitis.

Methods: The medullary cavity of the right tibia was inoculated with $10^{7} \mathrm{CFU}$ of methicillin-sensitive Staphylococcus aureus (MSSA-ATCC 29213) in 40 rats, and the rats were randomly divided into four groups according to treatment: group I, saline (control); group II, saline + MW therapy; group III, systemic cefuroxime; and group IV, systemic cefuroxime + MW therapy. MWs were applied for 20 min per day to the infected limbs, and all rats were sacrificed on the 7th day. The severity of tibial osteomyelitis was assessed by quantitative culture analysis.
\end{abstract}

Results: Bacterial counts in groups III and IV were significantly reduced compared with those in the control $(p=0.001$ and $<0.001$, respectively). Furthermore, significant differences were detected between groups III and IV $(p=0.033)$. However, the difference between groups I and II was nonsignificant $(p=0.287)$.

Conclusion: Our experimental model suggests that MW therapy provides a significant synergy for systemic antibiotic treatment. However, further clinical trials are required to safely use this treatment modality in patients.

Keywords: Microwave, Osteomyelitis, Staphylococcus aureus, Cefuroxime

\section{Introduction}

Osteomyelitis is an inflammatory disorder of the bone caused by infection [1]. It is still challenging for orthopaedic surgeons because of its protracted treatment process. The reported infection control rate ranges from 67 to 95\% [2], which means that $5 \%$ to $33 \%$ of patients suffer from recurrence of infection. In recent years, some new adjuvant treatments have been attempted to treat and cure osteomyelitis, for example, hyperbaric oxygen therapy, pulsed electromagnetic fields, ultrasound, laser, and extracorporeal shockwave, which have been demonstrated with successful results in the treatment of osteomyelitis [3-6]. Despite advances in surgical treatment, antibiotic therapy, diagnostic methods, and

\footnotetext{
*Correspondence: qiu_xusheng@163.com; chenyixin007@126.com 'Department of Orthopaedics, Nanjing Drum Tower Hospital, Clinical College of Nanjing Medical University, 321 Zhongshan Road, Nanjing, China Full list of author information is available at the end of the article
}

differentiated approaches to each type of osteomyelitis, the treatment outcomes are still unsatisfactory [7].

As we know, the local blood supply to the bone is impaired in patients with osteomyelitis [8-10]; therefore, strategies to improve blood supply and tissue perfusion will be beneficial to improve microbial clearance in infected areas and minimize recurrence in predisposed regions. The approaches to achieve this goal have typically been surgical, with transfer of tissue flaps and adequate debridement [10]. Microwaves (MWs) are non-ionizing electromagnetic waves with frequencies ranging from 300 to $300 \mathrm{GHz}$. The tissue can absorb the MW energy as vibrational energy. Due to the nature of the tissue, this vibrational energy is converted into perceivable warmth in the tissue. Hyperthermia induced by MW diathermy can increase the temperature of deep tissues, which contributes to a regional increase in blood flow. Effective clinical responses occur when the tissue temperature reaches 41 
to $45{ }^{\circ} \mathrm{C}$, and the blood perfusion increases by approximately 15 times [11]. Therefore, MWs may theoretically beneficial to the treatment of osteomyelitis. Furthermore, the MWs delivered from Prostatron version 2.0 (a computer-driven system, working frequency: $1296 \mathrm{MHz}$ ) with temperature no more than $44{ }^{\circ} \mathrm{C}$ showed a bactericidal effect in vitro on laboratory-cultured Escherichia coli and Enterobacter cloacae [12]. Considering the increased blood perfusion induced by MW diathermy and the possible bactericidal effect of MWs, a hypothesis was proposed that MWs may be an easy and effective adjuvant therapy for the prevention or treatment of osteomyelitis. Therefore, the present study aimed to investigate whether MWs may play a role in the treatment of acute bone infection in a rat model. The influence of MWs and a combination of MWs and systemic antibiotic treatment on acute bone infection were both investigated.

\section{Materials and methods}

\section{Bacterial strain and selection of antibiotic}

The bacterial strain selected in the study was the ATCCMSSA 29213 standard strain, which is one of the most common causative pathogens of bone infection and is resistant against many classes of antimicrobials [13]. Given that the purpose was to investigate the effect of systemic antibiotic treatment together with MWs, we chose cefuroxime, which can reach a certain concentration in bone tissue [14]. The minimum inhibitory concentration (MIC) of cefuroxime for the tested strain is $0.5-2 \mathrm{mg} / \mathrm{ml}$. After $24 \mathrm{~h}$ of incubation of the isolate at $37{ }^{\circ} \mathrm{C}$ (Thermo-3111, Thermo Scientific, USA), several colonies were added into sterile saline to form a $1 \times 10^{8}$ colony-forming units (CFU)/ml MSSA suspension, corresponding to a turbidity of 0.5 McFarland standards (DensiCHEK Plus, BioMérieux, Inc., USA).

\section{Animals and surgical procedure of acute bone infection}

Forty male rats at approximately the same age (280-310 g) were chosen for this study. All animal experiments were conducted in accordance with the approval of the Institutional Committee on the Care and Use of Animals of Nanjing Drum Tower Hospital, Nanjing University Medical School (issue 2018/04). For acclimatization, animals were fed standard rat chow and water and housed in cages with controlled temperature and a 12-h light/dark cycle for at least 1 week before the experiment.

The experimental model performed in this study was primarily based on the procedure described by Fukushima et al. [15]. Acute bone infection was induced in the tibiae under general anesthesia by weight-adapted intraperitoneal injection of $10 \%$ chloral hydrate, $350 \mathrm{mg} / \mathrm{kg}$ body weight (BW). Ibuprofen was given preemptively at the onset of surgery. Animals were prepared for surgery as follows: The right leg was shaved, and the site of operation was surgically sterilized and draped. Strict asepsis was required during the surgical procedure to avoid other microbial contamination. A $1.5-\mathrm{cm}$ longitudinal incision was made at the proximal metaphysis in the anterior tibia, and a hole was drilled through the cortex using a high-speed drill with a $0.7-\mathrm{mm}$-diameter bit. The medullary cavity contents were extracted using a 1-ml injection syringe, and then, $0.1 \mathrm{ml}$ of the $1 \times 10^{8} \mathrm{CFU} / \mathrm{ml}$ MSSA suspension was injected into the hole by an insulin injector. Afterward, the hole was sealed with bone wax. Finally, the fascia and skin were closed with sutures in sequence and disinfected.

Postoperatively, the animals received ibuprofen (15 $\mathrm{mg} / \mathrm{kg}$ BW daily) to control postoperative pain for 2 days. The rats were closely followed, and the wounds were observed every day. Their behaviors as well as weight were monitored regularly.

\section{Treatment modalities}

All animals were randomized and assigned to four groups as follows: group I was acute bone infection $+\mathrm{sa}-$ line (control); group II, acute bone infection + saline + MW therapy; group III, acute bone infection + systemic cefuroxime; and group IV, acute bone infection + systemic cefuroxime + MW therapy.

Saline and cefuroxime were administered immediately after the induction of acute bone infection, and MW therapy was conducted approximately $2 \mathrm{~h}$ after injection of saline and cefuroxime. Groups I and II received saline (30 ml/kg BW) daily. In groups III and IV, the daily dose of cefuroxime was $30 \mathrm{mg} / \mathrm{kg}$ BW. Saline and cefuroxime were administered by the intraperitoneal route.

The animals in groups II and IV received MW treatment every day after surgery. MW treatment was performed under general anesthesia. Only the right tibia received $\mathrm{MW}$ treatment (Fig. 1). The applicator was connected to a 2450 MHz-MW generator (WB-3100AI, Baoxin Medical Equipment Co., Ltd., Xuzhou, China) with power output ranging from 0-100 W. A 25-W continuous-wave MW exposure was used. The MW treatment lasted for 20 min per day. The non-contact applicator was parallel to the lesion and 8 $\mathrm{cm}$ away from the skin (Fig. 1).

After 7 days, radiographs were taken with rats in the prone position, and all rats were weighed and then sacrificed via rapid cervical dislocation. The tibiae were dissected and retrieved under sterile conditions for microbiologic analysis. The establishment of bone infection could be seen in the control group (Fig. 2).

\section{Microbiologic analysis}

Biopsy specimens of the infected tibiae were analyzed by microbiology procedures, and the microbiologist was blinded to the groups. Standard plate count analysis was performed. The tibiae were fragmented, and $10 \mathrm{ml}$ of 


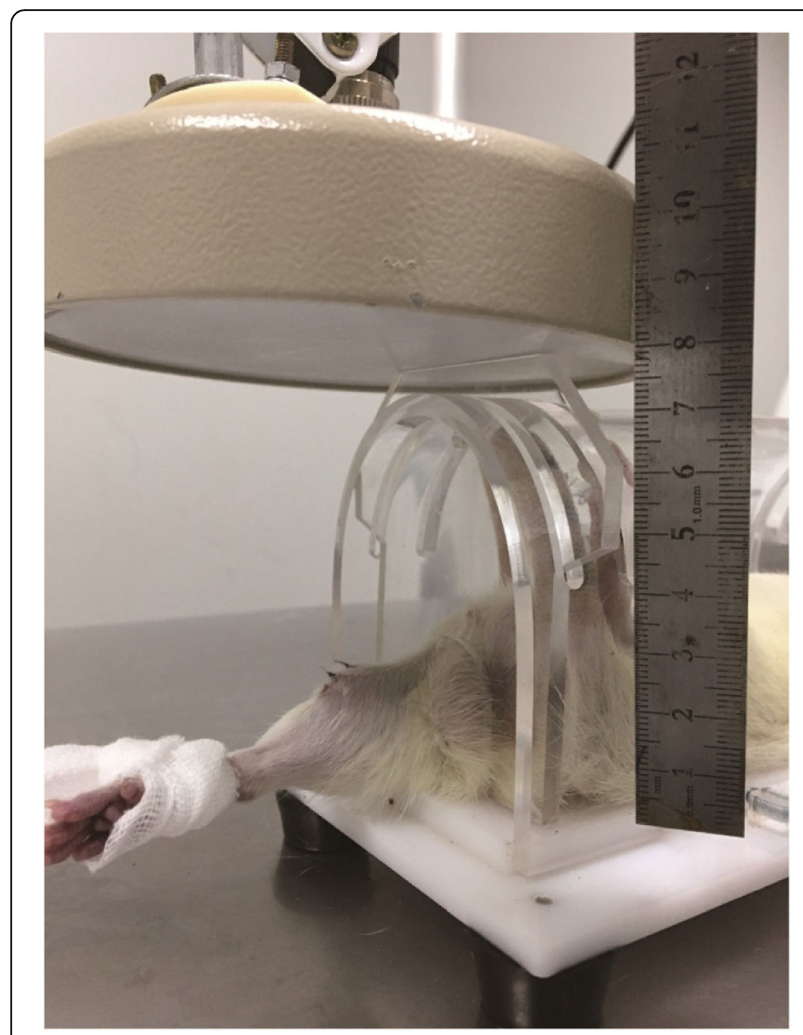

Fig. 1 The right leg of the rat underwent MW exposure sterile saline was added to a $15-\mathrm{ml}$ sterile centrifuge tube. The centrifuge tube was vortexed and homogenized, and then, 10-fold serial dilutions of $10^{-1}$ to $10^{-3}$ of the samples were prepared using sterile saline to accurately count the number of bacteria. Then, $200 \mu \mathrm{l}$ of each of these suspensions was streaked onto Columbia Blood Agar Base Medium (BioMérieux, Inc., USA) in duplicate. After 24 h of incubation of the blood agar plates at $37{ }^{\circ} \mathrm{C}$ (Thermo-3111, Thermo Scientific, USA), the colonies on the plates were counted and calculated as per milliliter of suspension (CFU/ $\mathrm{ml})$. Final identification was performed with a Vitek 2 compact system (BioMérieux, Inc., USA) for confirmation.

\section{Statistical analysis}

As the data were skewed, log transformation was applied for all the variables. All calculations were carried out using SPSS 22.0 (SPSS, Inc., Chicago, IL). Quantitative culture data are expressed as the mean and standard deviation (SD) of CFU. For group comparison, the analysis of variance (ANOVA) test was used. A $p$ value less than 0.05 was considered significant.

\section{Result}

Quantitative culture of excised tissues

No abnormal behavioral patterns, such as fatigue and aggressiveness, were observed among the rats during the course of these experiments. No animal displayed severe skin infection or died before sacrifice. The rats in groups I, II, and IV lost weight (mean $21 \mathrm{~g}, 31.7 \mathrm{~g}$, and $13.6 \mathrm{~g}$, respectively), while the animals in the antibiotic group gained weight (mean $4.8 \mathrm{~g}$ ). The $p$ values of weight changes between the groups are shown in Table 1 .
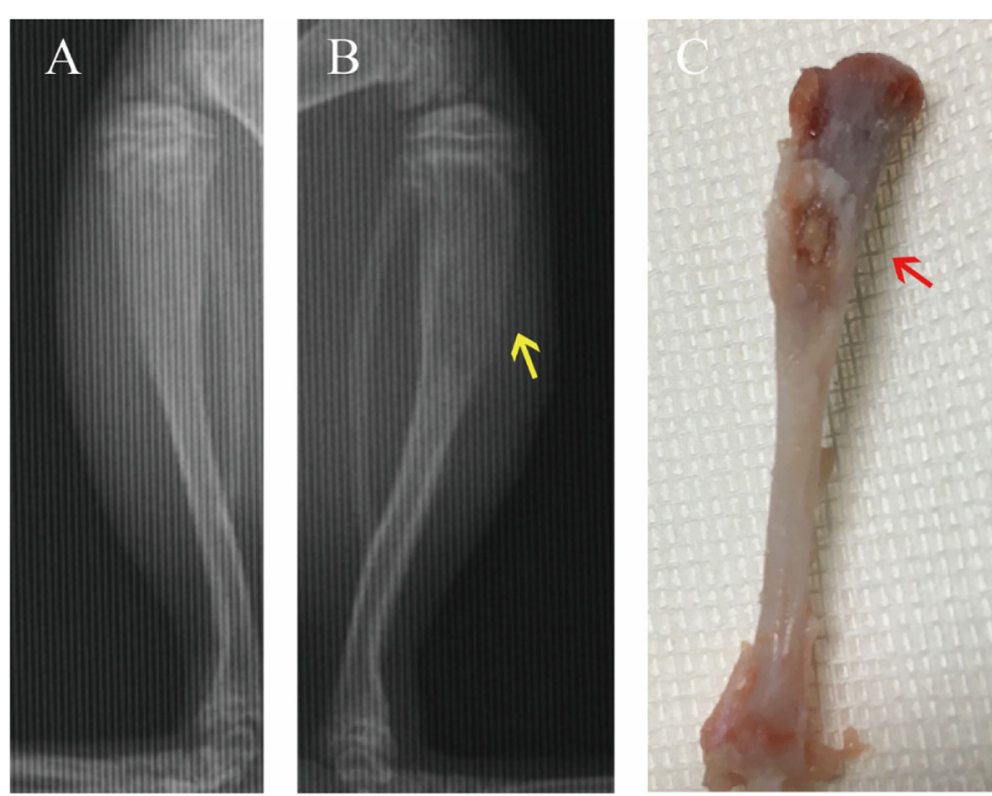

Fig. 2 Signs of bone infection in the control group. Skeletal changes were obscure on X-rays, but osteolytic change and bone destruction (yellow arrow) still could be seen (b) compare to the contralateral tibia (a); biopsy specimen showed pus (red arrow) on the proximal tibia (c) 
Table $1 p$ values between the groups according to weight changes

\begin{tabular}{llll}
\hline Group & Control & MW & $A B$ \\
\hline$M W$ & 0.223 & - & $<0.001^{\mathrm{a}}$ \\
$\mathrm{AB}$ & $0.005^{\mathrm{a}}$ & $<0.001^{\mathrm{a}}$ & - \\
$\mathrm{MW}+\mathrm{AB}$ & 0.392 & $0.043^{\mathrm{a}}$ & $0.04^{\mathrm{a}}$ \\
\hline
\end{tabular}

$M W$ microwave, $A B$ antibiotic

${ }^{a}$ The mean difference is significant at the 0.05 level

Table 2 presents the bacterial counts; compared with that in group I, the mean percent decrease in bacterial counts was $17.9 \%$ in group II, $56.4 \%$ in group III, and $89.7 \%$ in group IV. A significantly reduced bacterial count was found in group IV compared with those in the other three groups (Fig. 3). A statistically significant difference was noted between groups III and IV. Additionally, the mean bacterial number of group II was lower than that of group I, but no significant difference was detected. Table 3 lists the $p$ values of bacterial counts in paired comparisons of treatment groups.

\section{Discussion}

To our knowledge, this study is the first to demonstrate that MWs play a role in the treatment of bone infection in vivo. In this study, an acute osteomyelitis model was produced using an MSSA strain. One week after initiation of treatment, bacterial counts in group IV (cefuroxime $+\mathrm{MW}$ ) decreased significantly compared to those in the untreated control group, group II (MW) and group III (cefuroxime). These results demonstrate that cefuroxime + MW significantly reduced bacterial counts and that MW therapy provides significant synergy for systemic antibiotic treatment. In our study, the average bacterial counts in the "only MW" group were lower than those in the control group, although the difference was not statistically significant. Therefore, we concluded that the MW therapy did not promote bacterial proliferation or increase the spread of bacteria.

MW energy has been reported to be bactericidal to gram-positive and gram-negative bacteria in vitro $[12,16]$. In our study, the combination of cefuroxime + MW significantly reduced bacterial counts; two possible explanations account for this phenomenon. First, the temperature of saline in vitro can be achieved and maintained at $45{ }^{\circ} \mathrm{C}$ under $2450-\mathrm{MHz}-\mathrm{MW}$ radiation for $20 \mathrm{~min}$, and as the tissue temperature increases from 41 to $45{ }^{\circ} \mathrm{C}$, the blood perfusion increases by approximately 15 times [11]. This change can increase the local microcirculation in the irradiation area, which can heighten both the local antibiotic concentration and the anti-inflammatory or immune response [17] to achieve local or systemic bactericidal or bacteriostatic effects. In addition, hyperthermia could produce an increase
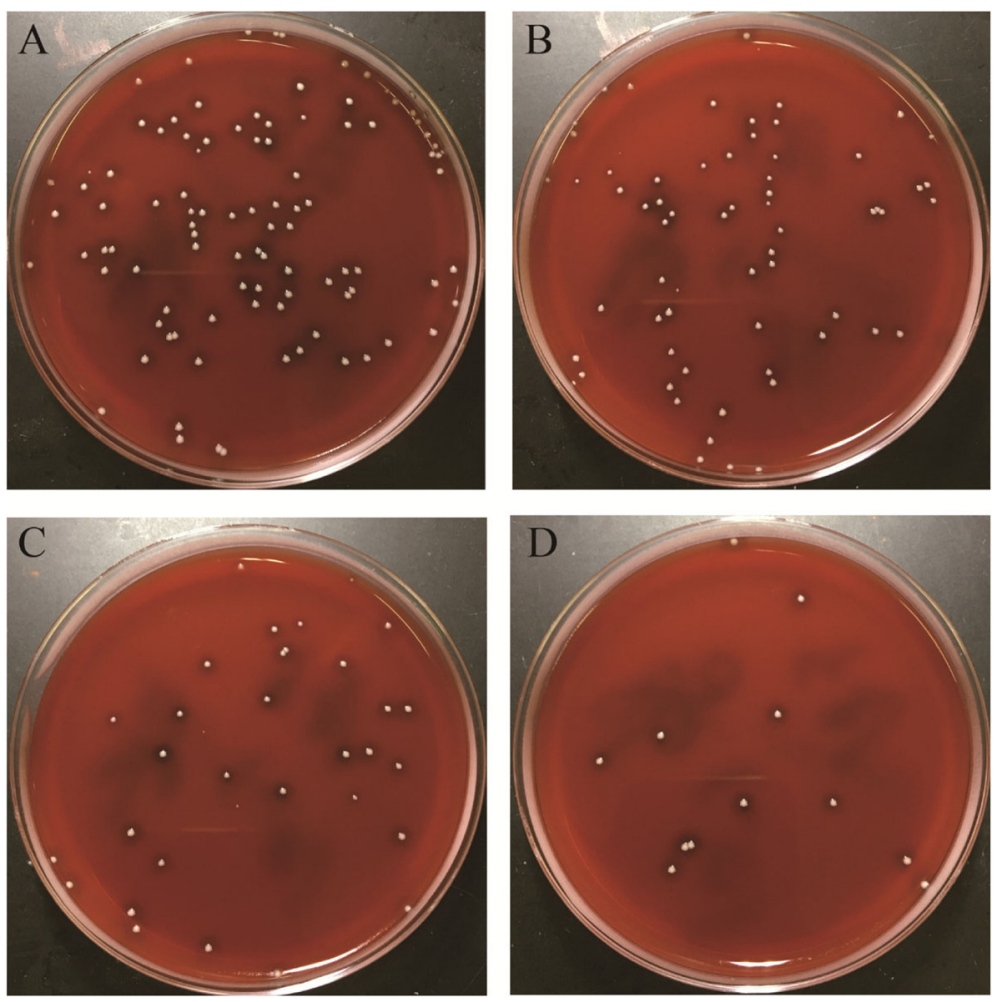

Fig. 3 Typical bacterial colonies grown on the blood agar plates (at serial dilutions of 10-3). a Group I without treatment. b Group || receiving only MW therapy. c Group III receiving only systemic cefuroxime. d Group IV treated with a combination of MW and systemic cefuroxime 
Table 2 Mean bacterial loads in treatment groups

\begin{tabular}{|c|c|c|c|c|c|}
\hline \multirow[t]{2}{*}{ Groups } & \multirow[t]{2}{*}{$n$} & \multicolumn{2}{|c|}{$\mathrm{CFU} / \mathrm{ml}\left(\times 10^{5}\right)$} & \multicolumn{2}{|c|}{$\log$ CFU/ml } \\
\hline & & Mean & SD & Mean & SD \\
\hline Control & 10 & 4 & 1.5 & 5.6 & 0.2 \\
\hline MW & 10 & 3.2 & 1.7 & 5.5 & 0.2 \\
\hline$A B$ & 10 & 1.7 & 1.1 & 5.1 & 0.5 \\
\hline$M W+A B$ & 10 & 0.4 & 0.5 & 4.4 & 0.5 \\
\hline
\end{tabular}

$M W$ microwave, $A B$ antibiotic, $S D$ standard deviation

in nutrients and oxygen in the heated region, which contributes to the effect of tissue repair. In addition, MWs also influence cytoarchitecture. Shamis et al. [18] used two microscopic analyses to evaluate the effects of MW radiation on $E$. coli cells at sub-lethal bulk temperatures, and the results suggested that temporary pores were formed within the cell membrane, resulting in a substantial increase in cellular permeability to ions and molecules during MW exposure. The pores in the cell membrane may make the bacteria more sensitive to antibiotics.

The results of weight changes demonstrated that there was a significant difference in the decrease in rat weight in group II (MW) compared to that in group III (cefuroxime) and group IV (cefuroxime + MW). Furthermore, a significant difference was found between group III (cefuroxime) and group IV (cefuroxime + MW), indicating that MWs may have an effect on rats to some extent. Hyperthermia caused by MWs induces a general increase in the metabolic rate [19]. A previous study reported that the biological effects caused by MWs were correlated with the power density, frequency, waveform, modulation, and duration of exposure [20]. Another study found that prolonged whole-body MW exposure of rats to a $2.45-\mathrm{GHz}$ frequency ( $2 \mathrm{~h}$ per day for 35 days) adversely affects the organs, including the brain, liver, kidney, spleen, and testicular organs $[21,22]$. In the present study, 2450-MHz-frequency continuous-MW exposure (20 min per day for 7 days) was used, and the temperature of saline in vitro was maintained at $45{ }^{\circ} \mathrm{C}$ under these conditions. This method corresponds to the practice that the temperature should not exceed $45^{\circ} \mathrm{C}$ for $30 \mathrm{~min}$ in musculoskeletal medicine [11]. No abnormal behavioral patterns or wound-related incidents were observed postoperatively. Therefore, we infer that MW therapy is relatively safe to apply under the condition of a $2450-\mathrm{MHz}$ frequency for $20 \mathrm{~min}$ per day $(8 \mathrm{~cm}$

Table $3 p$ values of bacterial counts in paired comparisons of treatment groups (log CFU/ml)

\begin{tabular}{llll}
\hline Group & Control & $\mathrm{MW}$ & $\mathrm{AB}$ \\
\hline $\mathrm{MW}$ & 0.545 & - & $0.034^{\mathrm{a}}$ \\
$\mathrm{AB}$ & $0.008^{\mathrm{a}}$ & $0.034^{\mathrm{a}}$ & - \\
$\mathrm{MW}+\mathrm{AB}$ & $<0.001^{\mathrm{a}}$ & $<0.001^{\mathrm{a}}$ & $<0.001^{\mathrm{a}}$
\end{tabular}

$M W$ microwave, $A B$ antibiotic, $S D$ standard deviation

${ }^{a}$ The mean difference is significant at the 0.05 level away from the skin). A histologic assessment should be conducted for further evaluation.

There are several limitations in the current study. First, staphylococci were selected in this study because they are the predominant bacteria in bacterial contamination of open fractures [23], but additional bacterial strains need to be investigated. Second, the small sample size of rats is another limitation of this study. Last but not the least, considering that the application of this treatment prevented bone infection in this study, further studies are needed to confirm its effect in curing clinical cases.

\section{Conclusion}

Based on the results above, the present study suggests that MW therapy may be a valuable auxiliary tool in the management of acute osteomyelitis, that it acts synergistically with systemic antibiotic treatment, and that this combination is safe in rats.

\section{Abbreviations}

AB: Antibiotic; ANOVA: Analysis of variance; BW: Bodyweight; CFU: Colony forming units; MHz: Megahertz; MIC: Minimum inhibitory concentration; MSSA: Methicillin-sensitive Staphylococcus aureus; MW: Microwave; SD: Standard deviation

\section{Acknowledgements}

None.

\section{Authors' contributions}

XYQ and XSQ participated in the study design. XYQ and JYJ contributed to the animal experiment. LMT and HFS conducted the microbiologic analysis. $X Y Q$ was in charge of interpreting the data analysis and drafting the manuscript. XSQ and XYC assisted in revising the manuscript. YXC and XSQ contributed equally to this work and XSQ should be considered cocorresponding authors. All authors read and agreed with the contents of the final manuscript.

\section{Funding}

This study was supported by the National Natural Science Foundation (81401793, 81572132), Young Talent Project (QNRC2016009), and Key Project supported by Medical Science and Technology Development Foundation (ZKX16034).

\section{Availability of data and materials}

All data generated or analyzed during this study are provided within this article.

Ethics approval and consent to participate

All animal experiments were performed in accordance with the ethical standards of Nanjing Drum Tower Hospital, Nanjing University Medical School.

Competing interests

The authors declare that they have no competing interests.

\section{Author details}

${ }^{1}$ Department of Orthopaedics, Nanjing Drum Tower Hospital, Clinical College of Nanjing Medical University, 321 Zhongshan Road, Nanjing, China. 2Department of Orthopaedics, Nanjing Drum Tower Hospital, The Affiliated Hospital of Nanjing University Medical School, 321 Zhongshan Road, Nanjing, China. ${ }^{3}$ Department of Surgery, The Affiliated Changzhou No. 2 People's Hospital of Nanjing Medical University, 68 Gehu Road, Changzhou, China. 
Received: 4 July 2019 Accepted: 21 August 2019

Published online: 06 September 2019

\section{References}

1. Rao N, Ziran BH, Lipsky BA. Treating osteomyelitis: antibiotics and surgery. Plast Reconstr Surg. 2011;127 Suppl 1:177S-87S.

2. Patzakis M, Zalavras C. Chronic posttraumatic osteomyelitis and infected nonunion of the tibia: current management concepts. J Am Acad Orthop Surg. 2005;13:417-27.

3. Inanmaz ME, Uslu M, Isik C, Kaya E, Tas T, Bayram R. Extracorporeal shockwave increases the effectiveness of systemic antibiotic treatment in implant-related chronic osteomyelitis: experimental study in a rat model. J Orthop Res. 2014;32:752-6.

4. Philandrianos G. Chronic nonhematogenous osteomyelitis treated with adjuvant $\mathrm{CO}_{2}$ laser sterilization: a preliminary report. J Clin Laser Med Surg 1992;10:439-44.

5. Mader JT, Adams KR, Wallace WR, Calhoun JH. Hyperbaric oxygen as adjunctive therapy for osteomyelitis. Infect Dis Clin North Am. 1990;4:433-40.

6. Emara KM, Ghafar KA, Al Kersh MA. Methods to shorten the duration of an external fixator in the management of tibial infections. World J Orthop. 2011;2:85-92.

7. Hogan A, Heppert VG, Suda AJ. Osteomyelitis. Arch Orthop Trauma Surg 2013;133:1183-96.

8. Birt MC, Anderson DW, Bruce Toby E, Wang J. Osteomyelitis: recent advances in pathophysiology and therapeutic strategies. J Orthop. 2017;14:45-52.

9. Lazzarini L, Mader JT, Calhoun JH. Osteomyelitis in long bones. J Bone Joint Surg Am. 2004;86-A:2305-18.

10. Fang RC, Galiano RD. Adjunctive therapies in the treatment of osteomyelitis Semin Plast Surg. 2009;23:141-7.

11. Giombini A, Giovannini V, Di Cesare A, Pacetti P, Ichinoseki-Sekine N, Shiraishi $M$, et al. Hyperthermia induced by microwave diathermy in the management of muscle and tendon injuries. Br Med Bull. 2007;83:379-96.

12. Sahin A, Eiley D, Goldfischer ER, Stravodimos KG, Zeren S, Isenberg HD, et al. The in vitro bactericidal effect of microwave energy on bacteria that cause prostatitis. Urology. 1998:52:411-5; discussion 415-6.

13. Soni I, Chakrapani H, Chopra S. Draft genome sequence of methicillin-sensitive Staphylococcus aureus ATCC 29213. Genome Announc. 2015;3:pii: e01095-15.

14. Kaukonen JP, Tuomainen P, Mäkijärvi J, Mokka R, Männistö PT. Intravenous cefuroxime prophylaxis. Tissue levels after one 3-gram dose in 40 cases of hip fracture. Acta Orthop Scand. 1995;66:14-6.

15. Fukushima N, Yokoyama K, Sasahara T, Dobashi Y, Itoman M. Establishment of rat model of acute staphylococcal osteomyelitis: relationship between inoculation dose and development of osteomyelitis. Arch Orthop Trauma Surg. 2005;125:169-76.

16. Zhou BW, Shin SG, Hwang K, Ahn JH, Hwang S. Effect of microwave irradiation on cellular disintegration of Gram positive and negative cells. Appl Microbiol Biotechnol. 2010;87:765-70.

17. Repasky E, Issels R. Physiological consequences of hyperthermia: heat, heat shock proteins and the immune response. Int J Hyperthermia. 2002;18:486-9.

18. Shamis $Y$, Taube A, Mitik-Dineva N, Croft $R$, Crawford RJ, Ivanova EP. Specific electromagnetic effects of microwave radiation on Escherichia coli. Appl Environ Microbiol. 2011;77:3017-22

19. Guy AW, Lehmann JF, Stonebridge JB. Therapeutic applications of electromagnetic power. Proc IEEE. 1974;62:55-75.

20. Kubinyi G, Thuróczy G, Bakos J, Bölöni E, Sinay H, Szabó LD. Effect of continuous-wave and amplitude-modulated $2.45 \mathrm{GHz}$ microwave radiation on the liver and brain aminoacyl-transfer RNA synthetases of in utero exposed mice. Bioelectromagnetics. 1996;17:497-503.

21. Zhi WJ, Wang LF, Hu XJ. Recent advances in the effects of microwave radiation on brains. Mil Med Res. 2017;4:29.

22. Chauhan $P$, Verma HN, Sisodia R, Kesari KK. Microwave radiation $(2.45 \mathrm{GHz})$ induced oxidative stress: whole-body exposure effect on histopathology of Wistar rats. Electromagn Biol Med. 2017;36:20-30.

23. Otchwemah R, Grams V, Tjardes T, Shafizadeh S, Bathis H, Maegele M, et al. Bacterial contamination of open fractures - pathogens, antibiotic resistances and therapeutic regimes in four hospitals of the trauma network Cologne, Germany. Injury. 2015;46(Suppl 4):S104-8.

\section{Publisher's Note}

Springer Nature remains neutral with regard to jurisdictional claims in published maps and institutional affiliations.

Ready to submit your research? Choose BMC and benefit from:

- fast, convenient online submission

- thorough peer review by experienced researchers in your field

- rapid publication on acceptance

- support for research data, including large and complex data types

- gold Open Access which fosters wider collaboration and increased citations

- maximum visibility for your research: over $100 \mathrm{M}$ website views per year

At BMC, research is always in progress.

Learn more biomedcentral.com/submissions 